\title{
EIDIA
}

Revista Eletrônica de Estudos Integrados em Discurso e Argumentação

dx.doi.org/10.17648/eidea-16-2226

\section{FASCISMO, POPULISMO: AS UTILIZAÇÕES CONTEMPORÂNEAS DE DUAS CATEGORIAS POLÍTICAS NAS MÍDIAS}

\section{Marc Angenot ${ }^{i}$}

Resumo: Proponho-me - em vinte páginas, posso apenas esboçar minhas análises - a descrever e dar razão aos usos atuais de duas palavras, que retornam continuamente e que pretendem classificar e estigmatizar ao mesmo tempo, possuindo uma longa história. Duas categorias políticas que retornam nas mídias, na esfera pública e nos trabalhos de estudiosos - dos quais eu falarei brevemente. O leitor compreenderá, sem esforços, porque devo realizar essa análise de fenômenos contemporâneos voltando, necessariamente, a 1945 e até mesmo antes desse período. Minha análise concentrar-se-á na Europa e na América do Norte nos séculos XX e XXI, que formam, mais especificamente, minha área de pesquisa.

Palavras-chave: Fascismo. Populismo. Usos. Mídias.

\begin{abstract}
I propose - I can, in twenty pages, just sketch my analysis - to describe and give reason to the current uses of two words that return continually and which intend to classify and stigmatize at the same time, - two words that have a long history. Two political categories that return in the media, in the public sphere and in the work of academic researchers - of which I shall speak briefly. The reader will understand, without effort, why I must carry out this analysis of contemporary phenomena, necessarily returning to 1945 and even before that period. My analysis will focus on Europe and North America in the twentieth and twenty-first centuries, which form, more specifically, my area of research.
\end{abstract}

Keywords: Fascism. Populism. Uses. Media.

\footnotetext{
' Docente da Universidade McGill, Canadá. E-mail: marc.angenot@mcgill.ca.
} 
EID\&A - Revista Eletrônica de Estudos Integrados em Discurso e Argumentação, Ilhéus, n. 16 esp. "Discurso e argumentação na política latino-americana, set.2018.

\section{Retórica da qualificação}

Seja no campo das ciências, na filosofia, nas instituições acadêmicas, nas ciências sociais e históricas, os mundos artístico e literário, em toda a parte e constantemente, rompem polêmicas, e se desencadeiam as controvérsias intelectuais, mais ou menos, esotéricas, muitas vezes veementes que, também frequentemente, deixam o empírico dos especialistas para ter sucesso na cena pública e se tornarem verdadeiros fenômenos sociais e políticos de média e longa duração.

No entanto, as controvérsias dos estudiosos e posteriormente controvérsias públicas, ressurgentes e irreconciliáveis, muitas vezes só dizem respeito à qualificação - no sentido jurídico deste termo - de um fato, de um ato, de um evento ou de um grupo de indivíduos, de uma entidade política. É este caso particular, caso muito comum na realidade, que será ilustrado em algumas páginas sobre duas etiquetagens políticas recorrentes. As controvérsias mais amargas e intermináveis se concentram com frequência (somente) sobre as palavras com as quais classificamos e designamos - e o amargo debate sobre as categorias e denominações começam "com um quarto de turno". A “qualificação jurídica” é, recordo, a operação que permite a aplicação de uma regra de direito apreendendo os elementos do fato e inscrevendo-os numa categoria de direito positivo, recorrendo, em especial, aos critérios jurisprudenciais. A atribuição de uma qualificação jurídica permite, por sua vez, a aplicação do regime jurídico correspondente, isto é, o conjunto de regras de direito aplicáveis a uma pessoa, uma organização, uma ação, etc. Eu proponho alargar o conceito além do mundo dos tribunais para aplicá-lo a um fenômeno difuso e permanente da vida intelectual e da vida em sociedade: as polêmicas mais intransponíveis e duráveis têm, muitas vezes, somente o objeto da pretensão de classificar desta ou daquela maneira e denominar. Raciocinar e argumentar, é de fato, no mais elementar destas operações, distinguir, identificar por uma palavra e classificar num paradigma semântico. Tudo começa na retórica, no discurso social, nas ideologias, dando nome às coisas, aos acontecimentos, aos grupos humanos, fazendo, por exemplo, com duas palavras, duas entidades distintas do que, segundo outras, é indissociável, do que forma as duas faces ou as etapas de um só processo. Ou, ao contrário, assimilando sob um só termo o que "tudo" deveria distinguir. Entretanto, nada, nem na linguagem como tal, nem na relação de inteligência com o mundo, não pró́be indubitavelmente de criar entidades 
EID\&A - Revista Eletrônica de Estudos Integrados em Discurso e Argumentação, Ilhéus, n. 16 esp. "Discurso e argumentação na política latino-americana, set.2018.

heterogêneas, distinções despropositadas e amalgamas falaciosas. Assim as polêmicas persistentes mantêm então - tecnicamente - somente uma definição divergente: um embrião é uma "pessoa humana"? Certamente, se sua definição de "pessoa humana" é feita para englobar o feto desde a concepção. Não se pode, de fato, refutar uma definição, mas simplesmente Ihe opor à outra.

Dentre as perspectivas metodológicas originais produzidas nas ciências humanas na Alemanha contemporânea, devemos mencionar os trabalhos de Reinhart Koselleck e de seus discípulos que desenvolveram uma problemática denominada Begriffsgeschichte, a história conceitual ou semântica histórica. No entanto, essa história é indissociavelmente uma história polêmica, uma história de polêmicas. Os Grundbegriffe, as categorias fundamentais de uma cultura política dada se evoluem somente nas controvérsias sucessivas altamente confusas, opondo classificações e definições contraditórias.

Exemplo, esboçado rapidamente, que figura na polêmica ela mesma interminável que pretende aproximar, sob o líder do "Totalitarismo", os regimes soviético/estalinista e nazista: a Kolyma foi uma rede de "campos" no sentido onde Buchenwald (ou Treblinka, o que faz dois) foram os "campos"? Outro exemplo: os genocídios da Tasmânia, os Sioux e os índios das planícies, os Armênios, os Judeus, os Ciganos, os Ucranianos dos anos vinte, os Cossacos e outros povos soviéticos "punidos", aqueles dos Tutsis estão no mesmo título de definição de "genocídios". Questão jurídica de aparência, mas que é asperamente debatida pelos historiadores e pelos cientistas políticos não menos que no grande público com as suas polarizações políticas. O massacre dos culaques pelos bolcheviques foi um "genocídio de classe"? (Ernst Nolte dixit)? A mesma essência apesar dos acidentes diferentes, para falar como os aristotélicos? Ou o sintagma de "genocídio de classe" é um absurdo em si mesmo? Questões de forma jurídica ainda, não menos que, predominantemente políticas, acompanhadas, a partir de então, de controvérsias intermináveis.

\section{Breve histórico dos usos e abusos de "fascismo"}

O primeiro encontro de um movimento que foi batizado Fasci italiani di combattimento, é convocado pelo então socialista transformado em líder nacionalista e belicista Benito Mussolini em 23 de março de 1919, na Piazza San Sepolcro em Milão. Um registro policial assinala a presença de 300 pessoas. Os 
EID\&A - Revista Eletrônica de Estudos Integrados em Discurso e Argumentação, Ilhéus, n. 16 esp. "Discurso e argumentação na política latino-americana, set.2018.

fascistas são, inicialmente, um simples encontro - entretanto, a palavra comportava um outro sentido virtual e (sem que o deslizamento seja datado) os ainda nominados fascistas, reinvindicam-se patrioticamente da glória da Roma antiga, vão determinar acima de tudo fascio-encontro pela lembrança do fasci dei Littori os feixes dos lictores romanos.

Entre 1919 e 1945, vários partidos de milícia violentos e vários regimes nacionalistas autoritários, anti-parlamentaristas, anti-socialistas foram observados em outros lugares da Europa, — um só se designa, entretanto, ele mesmo como fascista do Fascio italiano di combattimento no Partito nazionale fascista fundado em 1923. Ao final dos anos 1920, fascismo (e seus equivalentes em diferentes línguas) iniciou, de fato, sua complexa extensão genérica além do "caso" italiano. A palavra foi posta a designar pelo público politizado - ainda que as aplicações sejam imediatamente contestadas - os regimes autoritários, "bonapartistas", dizem, às vezes, ultra-nacionalistas certamente, xenófobos, anti-bolcheviques, anti-socialistas e antiparlamentares como os vemos se estabelecerem aqui e ali na Europa sobre as ruínas das democracias instáveis e, mais ou menos explicitamente sobre o bem sucedido "modelo" italiano. É necessário delimitar para esses regimes uma ou várias categorias genéricas ou destacar apenas suas diferenças irredutíveis? O tipo ideal que avançaremos servirá a apagar, a obliterar essas diferenças ou ele permite ao contrário pensar nelas? Há, distingue-se às vezes, um liberalismo europeu bastante coeso, uma internacional socialista, mas havia os fascismos. Se os fascismos são, de fato, os "ultranacionalismos" e se cada nacionalismo se esforça para ser único, se esses motivos de ressentimento, esses temas reivindicadores e esses objetivos dependem necessariamente de uma cultura nacional no que ela tem de particular, o fascismo genérico e o nacionalismo são generalidades sem objeto? Todos os regimes ditos fascistas foram diferentes, mas não é estéril de se manter as singularidades para jamais as confrontar e as comparar?

A perpetuação do antifascismo após o desaparecimento dos regimes nazistas e mussolinistas fez aparecer na Europa um duplo uso, ao mesmo tempo complementar e conflituoso, que permitia todos os deslizamentos e todas as confusões. Ele serviu simultaneamente (1) aos comunistas ocidentais, de média eficácia de intimidação face à esquerda e face aos "anticomunistas primários" nos seus níveis, automaticamente acusados de serem simpatizantes fascistas, e (2) serviu simultaneamente de "cimento" à 
EID\&A - Revista Eletrônica de Estudos Integrados em Discurso e Argumentação, Ilhéus, n. 16 esp. "Discurso e argumentação na política latino-americana, set.2018.

esquerda colocada em bloco, serviu para lhe dar a ilusão de ser definitivamente unida enfrentando um inimigo comum para além de suas desconfianças, suas divisões e seus desentendimentos. Forçando apenas o trato, poderíamos sustentar a tese de que a história do antifascismo na França se reduz a uma história dupla, resume o historiador das ideias Pierre-André Taguieff: por um lado, aquela das reações mais ou menos orquestradas contra o anticomunismo, e, por outro lado, aquela da construção, pela esquerda, de sua identidade fantasiada contra um inimigo mítico, permitindo lançar uma suspeita permanente sobre a direita, que visar "derivar" constantemente em direção a formas extremistas e ser regularmente apreendidas pela "tentação fascista" (TAGUIEFF, 2007, p. 185). Face ao anticomunismo relançado no ocidente sob a hegemonia EUA pela Guerra fria, os partidos comunistas, na Europa ocidental, onde eles eram poderosos, tinham então ressuscitado o fascismo que acabava aparentemente de desaparecer, vencido, esmagado pela aliança dos democratas e do regime estalinista, - eles ressuscitaram como um espantalho e serviram para etiquetar tudo o que lhes desagradavam e estigmatizar qualquer um que se vinculasse a eles e/ou à URSS. Os comunistas vão - confiscar a seu proveito a complexa memória da luta antifascista dos tempos de guerra; - censurar a lembrança de suas violências contra os socialistas, os trotskistas, os sindicalistas-revolucionários, em especial na Espanha e - reprimir a todo custo memória do Pacto Molotov-Von Ribbentrop, qualquer um que lembrasse esses três anos de aliança sangrenta entre Hitler e Stalin estando automaticamente denunciados como um odioso "fascista". A acusação de "fascismo", tornou-se essencialmente sinônimo de anticomunista, continuará por muito tempo sendo um meio eficaz de intimidação dos social-democratas e dos democratas liberais como de censura das diversas correntes oposicionistas. Desde 1935, a URSS foi apresentada como o paladino e o líder do antifascismo, - ela vai manter essa imagem mais do que nunca quando ela aparecer depois de 1945 como o principal vencedor do nazismo, vencedor ao preço de imensos sofrimentos de povos soviéticos. O sistema comunista tira da vitória contra os nazistas sua justificação moral, para além dos fracassos e dos "excessos", justificação que persistirá melhor ou pior até o dia de seu depósito do balanço em 1991.

A repulsão intimidadora da categoria alternativa, aquela do "totalitarismo", categoria atribuída a um punhado de Cold Warriors US, foi indispensável para a manutenção deste posicionamento. Mas esta é uma história que eu não posso abordar... 
EID\&A - Revista Eletrônica de Estudos Integrados em Discurso e Argumentação, Ilhéus, n. 16 esp. "Discurso e argumentação na política latino-americana, set.2018.

Em sequência, diz que o antifascismo que tinha o éthos comum dos democratas antes e depois da guerra, como o formula Enzo Traverso, se congela em ideologia de Estado de países do Pacto de Varsóvia. Ele é utilizado paralelamente como arma intimidadora pelos partidos comunistas ocidentais face a seus adversários, quaisquer que sejam, periodicamente acusados com gritos estridentes de criticar a URSS unicamente para estabelecer o "fascismo" aqui em baixo. Esta dupla instrumentalização ao modo soviético comprometeu sua legitimidade. O "fascismo" instrumentalizado depois de 1945 foi, portanto, essencialmente centrado no nazismo, encarnação do mal absoluto. A ponte das correntes em Budapeste possui uma placa “DESTRUÍDA PELOS FASCISTAS EM 17 DE JANEIRO DE 1945. Não são os italianos evidentemente que passaram por lá! O pós-guerra se fabrica ainda, por um consenso que vai dos comunistas aos democratas de todas as nuances, um fascismo retrospectivo cujo tipo conseguido é, de fato, o nazismo. O muro de Berlim erigido no centro da capital prussiana em agosto de 1961 pela República democrática alemã será nomeado oficialmente pela RDA como "Muro de Proteção Antifascista", antifaschistischerSchutzwall. Os fascistas que agora ameaçavam do outro lado do Muro eram os "vindicadores" alemães sustentados pelo imperialismo americano.

Na propaganda da Guerra Fria, são os Estados Unidos que se tornam o líder do renomado e ameaçador "fascismo mundial" em progresso, aliados aos "vindicadores" da Alemanha federal. Na mesma época, todos os movimentos de oposição e de resistência, duramente reprimidos, no regime do Pacto de Varsóvia são qualificados automaticamente de "fascistas". A revolução húngara de 1956 é ainda denunciada como o fato de fascistas e contrarrevolucionários. É em nome do antifascismo que será conduzida a repressão sangrenta da insurreição. É em seu nome que os partidos comunistas do mundo inteiro serão unânimes para aprovar o massacre. Os "fascistas" serão, em sequência, os críticos da repressão soviética em Budapeste.

\section{Usos científicos por meio século}

Eu não abordarei aqui a história muito complexa das dissensões científicas de mais de meio século ao qual já consagrei dois livros. Essas dissensões são paralelas aos debates públicos. É precisamente um bom exemplo de polêmicas paralelas de média duração, uma proliferando nas 
EID\&A - Revista Eletrônica de Estudos Integrados em Discurso e Argumentação, Ilhéus, n. 16 esp. "Discurso e argumentação na política latino-americana, set.2018.

mídias, na esfera pública com suas ideologias em conflito - e a outra na esfera acadêmica que pretende o retrocesso crítico e que recusa as simplificações e as instrumentalizações políticas do categorema.

Fascismo é um termo que é de um lado ao outro histórico, a saber que não é deduzido nem do entendimento nem do senso comum, mas que permite reagrupar os regimes políticos presentes ou erradicados, que são dados por essencialmente equivalentes e co-inteligíveis segundo os parâmetros que tem sentido apenas na história. Dito de outra forma, nenhuma arbitragem lógica decisiva não permite reter ou descartar de forma conclusiva as razões avançadas pró \& contra. Um historiador inglês, Stanley Payne comparou as definições científicas de "fascismo" por meio século, definições sucessivamente invalidadas pelas objeções de uns e de outros, a um campo de batalha ao cair da noite, coberto de carcaças de armamento sem uso e abandonadas. Anthony James Gregor consagrou já há mais de quarenta anos um livro que confronta as diversas Interpretações do Fascismo e estas proliferaram desde então. Encontra-se em inglês uma antologia em cinco grandes volumes, compilados há alguns anos, que reúne todas as definições e interpretações de "fascismo", monumento devastador vestido com intermináveis controvérsias históricas.

A dificuldade fundamental nos debates acadêmicos e fonte de polêmicas científicas inesgotáveis resultam precisamente do fato de que "fascismo" é uma palavra já supersaturada de sentido, de interpretações e definições em conflito, cheio de polêmicas, quando o historiador e o cientista político após 1950 se confrontam, uma palavra que os agentes e os grupos que vão estudar tem sempre já excessivamente utilizado na controvérsia e no ódio.

\section{América Latina}

Algumas palavras sobre a aplicação de "fascismo" na América latina: eles ilustrarão a questão complicada e infinitamente debatida da legitimidade da extensão e da transposição. Se a maioria dos historiadores europeus constroem o fascismo como um fenômeno limitado à Europa e própria a este continente, é que muitos historiadores de outros continentes importaram o conceito para caracterizar os regimes e os partidos estabelecidos nas suas regiões nos anos 1930 e 1940 e mais além. A ideia de um fascismo global ou planetário, de uma difusão de ideias e de modelos de ação (italianos principalmente; posteriormente as doutrinas franquista e salazarista) e de 
EID\&A - Revista Eletrônica de Estudos Integrados em Discurso e Argumentação, Ilhéus, n. 16 esp. "Discurso e argumentação na política latino-americana, set.2018.

uma implantação ativa fora da Europa parece progredir hoje em dia na pesquisa. É principalmente o Japão dos anos 1930-40, a África do sul do Apartheid e a América latina, do México à Argentina, que são estudados no contexto de um uso comparatista extensivo.

O debate aqui remonta aos anos 1930 mesmo quando a etiqueta do "fascismo" se encontra associada pelos observadores a diversos regimes autoritários e ultra nacionalistas no Brasil, na Argentina, no Chile, na Bolívia e no México. A América do sul conhece, tradicionalmente, os caudilhismos dos quais alguns entre as duas guerras inspirar-se-ão em Roma ou em Berlim e receberão mesmo o apoio, especialmente financeiro. Deve-se falar automaticamente de fascismos? A presença, nesses países, de fortes minorias italianas e/ou alemães favorecia aparentemente o "mimetismo". Com o Estado novo de Getúlio Vargas no Brasil em 1937 e a eleição de Juan Péron na Argentina em 1946, a América latina apresenta aos historiadores dois casos de tomada de poder "violentos" por um líder carismático, poderes cuja natureza e identidade permanecem debatidas. O francês Pierre Milza endossa um só caso indiscutível: "um só país, o Brasil, conheceu um verdadeiro fascismo de massa" com o integralismo de Salgado. Este não conseguirá, entretanto, tomar o poder, será Getúlio Vargas que instaurará em seu lugar e espaço o que Seymour Lipset denominou estranhamente de um "fascismo de esquerda", o Estado novo. Outros movimentos inspirados, por exemplo, em Mussolini e em Hitler (através de comunidades imigrantes e de milhões de indígenas reacionários) se desenvolveram, entretanto, nos mesmos anos de 1930 no Cone sul - como o Movimento nacional socialista chileno.

Finalmente, um só regime da América latina fez o objeto de vários livros e discussões persistentes quanto ao seu pertencimento ou não ao fascismo: Aquele de Juan Domingo Peròn na Argentina de 1946 à 1955. A ditadura de Peròn foi amplamente qualificada de "fascista" pela imprensa americana e europeia em seu tempo. As semelhanças com o recém falecido regime de Mussolini foram chocantes. Juan Domingo Peròn foi adido militar na Itália e admirou o regime. Pode-se fazer objeções no entanto: primeiramente, o regime peronista não era nem belicista nem expansionista. Num país onde golpes militares se sucederam com regularidade desde a deposição pelo exército, que instalou o general Uriburù, do presidente Hipòlito Irigoyen em 1930, o regime de Péron aparece sobretudo menos autoritário e brutal que seus antecessores. Especialmente, o regime se beneficiou do apoio inabalável 
EID\&A - Revista Eletrônica de Estudos Integrados em Discurso e Argumentação, Ilhéus, n. 16 esp. "Discurso e argumentação na política latino-americana, set.2018.

dos sindicatos, - juntamente com o do exército. Seymour Lipset avançou então o conceito de um "Fascism of the Left" - é um oxímoro pouco defensável, não mais do que o "Fascismo Proletário" de Anthony Joes. A mobilização em torno do regime de classes plebeias e sub-proletarianas lembra um pouco o fascismo, mas o apoio do trabalho organizado o contradiz igualmente as diversas legislações sociais que se credita ao justicialismo. Para Kevin Passmore, em Fascism: A Very Short Introduction, o regime não foi "nem totalitário nem fascista" Roger Griffinnão o acha suficientemente "palingenésico" nem radical. Para Stanley Payne, o peronismo apresenta características que a maior parte dos historiadores atribuem ao fascismo, mas sua base ao mesmo tempo militar e sindical a faz um caso muito incomum. Novo caso de perplexidade de especialistas, em que alguns se escapam hoje em dia com a classe à tout faire da política latino-americana, o "nacionalpopulismo".

Os historiadores do subcontinente fizeram outros neologismos compostos para qualificar os regimes empunhados antes e sobretudo após a guerra. O epíteto de "colonial-fascismo" foi atribuído em 1967 por Helio Jaguaribe no primeiro governo militar do Brasil e depois um certo número de especialistas criaram novas expressões, como "fascismo dependente", "fascismo atípico", "neo-fascismo", fascismo sui generis", a fim de caracterizar os novos regimes latino americanos estabelecidos após a guerra, especialmente no decorrer dos anos 1970, não mais em referência à Roma ou à Berlim, mas com a "benção" de Washington, centro do imperialismo mundial - enquanto que outros historiadores, insatisfeitos com a recorrência ao fascismo pelo regimes incapazes de comandar um verdadeiro apoio popular, nem de abordar decididamente a "questão nacional" em razão de sua dependência para com Washington - os regimes, de certo modo, nem sequer fascistas, - trabalham as categorias alternativas de regimes "autoritários", "burocrático-autoritário", "populismo", caudilhismo.

Os "Developmental theorists" redefinem às vezes o fascismo como uma ditadura mobilizadora e modernizadora nos países que passam do estado agrário ao industrial. Nesse caso, o sentido de "fascismo" não é integralmente pejorativo e o conceito, de larga extensão, permite integrar um grande número de regimes do Terceiro mundo (que são declarados, de fato, frequentemente "socialistas") nos anos 1950 e subsequentes, de N'krumah à Gamal Abdel Nasser' - regimes que, devidamente, emularam, com variados 
EID\&A - Revista Eletrônica de Estudos Integrados em Discurso e Argumentação, Ilhéus, n. 16 esp. "Discurso e argumentação na política latino-americana, set.2018.

resultados, o voluntarismo planista estalinista, terror e desprezo pela vida humana inclusive - e que coloca a questão da convergência de modelos projetados de direita e de esquerda.

A maior parte das ditaduras pessoais da América latina que se observa após 1945, abrangem os "regimes sultânicos": o conceito foi desenvolvido por Juan Linz. São os regimes de incompetência e servidos de presa a países cuja a ineficácia corrompida e a criminalidade absurda não permitem sequer os qualificar como "fascistas". Nós pensaríamos como encarnação do "tipo ideal” à República Dominicana de Rafael Trujillo, mas seu vizinho François Duvalier e o grotesco "duvalierismo" não são maus.

O regime de Paz Estenssoro na Bolívia, nos anos de 1950, foi etiquetado algumas vezes como "fascista" - a menos que não se assimile na vasta família à tout faire os "populismos" latino-americanos, categoria discriminada por vezes em "direita" e "esquerda", da qual aumentaria hoje o demagógico e brutal sistema "bolivarista” de Hugo Chaves e seu sucessor na Venezuela.

5. Avatar e decomposição de "fascismo" na esfera política: a "injúria suprema"

Após a guerra mundial, as lembranças aterrorizantes do fascismo/nazismos vão se encontrar determinadas e parcialmente obliterada, após um período de repulsão, pela recordação cada vez mais lancinante, pela hipertimésia de Shoah' A Shoah tornou-se a figura, por excelência, do $20^{\circ}$ século-Barbárie e ela terminou por operar como uma tela-lembrança - porque decretada "inconcebível” e ofuscante tudo o que há por trás e ao lado. Especialmente a covarde ou maquiavélica inércia das democracias enquanto o massacre estava se perpetrando. O fascismo severo anterior a Guerra legou, ainda, não somente aos comunistas, mas às esquerdas europeias, desde os mais radicais até os mais moderados após 1945, uma categoria nebulosa em perpétua expansão, um "fascismo" sem margem que se tornou a "injúria suprema" semeada a qualquer vento, tudo estando cada vez mais esvaziado de sentido. "Na França, nós somos sempre, ou fomos, o fascista de alguém", dir-se-ia. Pascal Ory se mostra irritado: ao final do século XX, ele ironiza, os esquerdistas identificaram a democracia ocidental e seus vínculos com Mercado no "fascismo" e no "nazismo" renovado - e seus adversários replicam qualificando de "fascista" ou de "totalitário" a retórica violenta de contestação esquerdista. Quase todos puderam um dia ou outro ser 
EID\&A - Revista Eletrônica de Estudos Integrados em Discurso e Argumentação, Ilhéus, n. 16 esp. "Discurso e argumentação na política latino-americana, set.2018.

qualificados de "facho" ao ponto que a deriva, os cortes semânticos tiveram que se encontrar identificados pelos dicionários. Consultemos Le Robert:

\footnotetext{
"Fascismo adquiriu, a partir dos anos 1960, valores afetivos no discurso político. Ele se emprega hoje para toda atitude política conservadora e autoritária e, de forma polêmica, para toda doutrina ou comportamento oposto à "esquerda". Ainda mais amplamente, fora de todo contexto político, é utilizado para falar de uma coerção, de uma autoridade imposta".
}

A ideia comunista pertence a "um círculo inteiramente fechado de imaginação política moderna”, diagnostica François Furet. Mas é curioso que desse naufrágio ideológico integral flutua, entretanto, ao final do século $X X$, um insubmersível antifascismo cujo ressurgimento, fraseológico pelo menos, é atestado todos os dias na imprensa francesa. No decorrer do lento e longo declínio, ao longo de meio século da "ideia” socialista e de esperanças que ela carregava, um antifascismo elementar - a denúncia mecânica de um fascismo sempre ressurgente - flutua só no meio de ruínas, da obsolescência, da dissolução, do abandono de grandes teorias e doutrinas de outrora. Ele se parece a uma tábua de salvação a qual se une à esquerda quando os contornos de Grandes esperanças foram dissipados.

A crítica deste abuso em função intimidadora resultou no processo de um antifascismo impostor, manipulado pelos comunistas e pelos esquerdistas, processo que começou a se instruir nos anos de 1970. Nós assistimos, pretendemos constatar, desde a queda dos regimes efetivamente fascistas, a uma vã "multiplicação de fascismos imaginários". O antifascismo pela força do abuso se encontrou reduzido a ser um miserável "conjunto de atitudes mentais, de representações estereotipadas e de crenças "sloganizadas" que Pierre-André Taguieff mostra nocivas a vida cívica não menos que absurdas. Todo regime repressivo é "fascista" para a extrema esquerda exceto, tão brutais e sanguinários eles são, aqueles que tem a boa ideia de se fingir de esquerda, ou ao menos, anti-imperialistas, a quem ele é muito perdoado.

A unanimidade antifascista persistente é criticada por aqueles que pensam que perante as formas de horror contemporâneo - Ruanda, Darfur, o terrorismo islâmico, a lista é longa -o antifascismo de rotina é ao mesmo tempo equivocado e hipocritamente nostálgico de tempos heroicos anteriores. Iniciado em tragédia por volta de 1930, o antifascismo se perpetua em uma interminável palhaçada. O velho consenso antifascista é também o alvo de moralistas anti-totalitários que, desde os meados dos anos de 1970, denunciando A barbárie com um rosto humano, pretendem reenviar "dois a 
EID\&A - Revista Eletrônica de Estudos Integrados em Discurso e Argumentação, Ilhéus, n. 16 esp. "Discurso e argumentação na política latino-americana, set.2018.

dois" ("dos à dos") fascistas e antifascistas estalinistas e associados, adversários decretados intercambiáveis no seu comum desprezo de homens e seu gosto pelo nepotismo de Estado, a violência e os massacres de massa.

Mais a época dos fascismos, que ensanguentaram a Europa, se distanciava no tempo, mais o fascismo como regime e como movimento saía do horizonte de ameaças reais, mais uma parte da esquerda ocidental se amedrontou com um sorrateiro "perigo fascista", vindo de todo lugar. A Besta imunda estava acordando. A ameaça estava escondida em cada um de nós. Era suficiente fazer um exame de consciência para sentir em si um terrível potencial fascista inconsciente! É especialmente um lugar comum angustiante, obsessivamente repetida nos ambientes maoistas dos anos de 1970. Ele é formulado nesses termos em junho de 1975 pelo romancista francês Philipe Sollers, convertido por um breve momento e cuja tolice astuta marcou a época: "O fascismo está presente em todos os lugares, a cada instante; ... ele está no interior de cada um; ... ele pode se manifestar lá onde nós menos esperamos, como um germe. A consciência vigilante do esquerdista estava assombrada pelo medo do "deslize" que revelaria seu fascismo interior; ela estava sujeita à obrigação de denunciar em alta voz todo "deslize" caracterizado - ou suspeito - nos outros.

Um derivado de "fascismo" se propaga, então, no decorrer dos anos de 1970, e a "fascização", que se encontra nos sintagmas "fascização das mentes, da sociedade", sempre acompanhada de " paulatina" ou de " crescente". "Fascização" exprime essa angústia perpétua de um fascismo iminente, de uma "deriva fascista" que identificam sinais de alerta, de "derrapagens" verbais, afirmações controversas - racistas, anti-semitas, homofóbicas, islamofóbico, porque "o fascismo" é sinônimo agora destes quatro líderes de acusação atualmente. Ainda a "fascização" em curso da Europa, da França (ou de Israel, ou dos Estados Unidos" é denunciada em dezenas de sites da web. Tal é, na minha opinião, o terreno ansioso obsessivo que preparou a forte censura "politicamente correta" das décadas seguintes.

Para o adolescente de 1968 todo coagido, toda expressão de autoridade, do pai, do professor, do policial permitia gritar "fascismo". Aqueles que utilizaram sobremaneira, a torto e a direito, este termo infeliz, sabem de seu sentido esvaziado, mas eles sentem que a título de denúncia suprema, de concerto com o nome menos dessemantizado "racista", ele conserva um poder intimidador, um poder de incômodo. "Racismo/ista" foi provocado, de 
EID\&A - Revista Eletrônica de Estudos Integrados em Discurso e Argumentação, Ilhéus, n. 16 esp. "Discurso e argumentação na política latino-americana, set.2018.

fato, no mesmo tipo de diluição e de desvalorização, na mesma medida em que um outro ativismo anti-, o "antirracismo", em progresso na Europa nos anos de 1980, levou ao aumento de um antifascismo bem fatigado. Ele também seguiu devidamente o declive de instrumentalização desenfreada e de perda semântica concomitante.

Os Sex Pistols ingleses cantavam outrora, com a convicção confusa da juventude, God Save the Queen and her Fascist Regime. Para Roland Barthes, preocupado em agradar a juventude apaixonada pela linguística, "a língua é fascista", amável infantilidade da qual se lembra um pouco, e para a antipsiquiatria dos anos 1970-80, todo psiquiatra era um fascista. Atualmente, o primeiro ministro italiano deposto Silvio Berlusconi é um "fascista" (nós o reprovaremos no melhor direito de ser um hiper-liberal corrompido.) Nicolas Sarkozy foi denunciado como tal em mais de um site de esquerda; www.syti.net inventou para o antigo presidente a categoria engraçada de "liberal-fascista" porque, nós explicamos, "o neoliberalismo hoje é o fascismo". A luta contra um fascismo onipresente, mas cada vez mais evanescente se perpetua ainda à extrema esquerda. Navegue na internet. Endehors.org denuncia, por sua vez, o "fascismo" de feministas radicais. O site ambientalista encontrou outros novos "fascistas" para esmagar: são os Global Warming Skeptics, qualquer um que duvidar do aquecimento climático mas www.ecofascism.com responde imediatamente: "Environmentalism is fascism!" Israel é um Estado "fascista" e produtor de "genocídio" além disso nas dezenas de sites de internet que se dizem de esquerda radical. Os sites contra o "fascismo sionista" o disputam não obstante aos sites sobre "o islamo-fascismo". Alcorão igual fascismo? coloca no topo da página www.contrelislam.org. A política americana é "fascista" desde sempre. "Genuine American fascists are on the run". "America is succumbing to Fascism", clama Naomi Klein em 2007. O categorema-injúria continua um pouco, mas lentamente sobre isso lançado.

A longo prazo, os conservadores compreenderam a coisa e os EUA, eles denunciam agora os liberais como os "únicos verdadeiros fascistas"! Veremos esta previsível manobra de retorsão no Liberal Fascism de Jonah Goldberg: a esquerda americana não parou, de Roosevelt à Hillary Clinton, de defender os princípios "remarcavelmente semelhantes" aos de Hitler e de Mussolini, expõe essa obra de tom e pretensão acadêmica. 
EID\&A - Revista Eletrônica de Estudos Integrados em Discurso e Argumentação, Ilhéus, n. 16 esp. "Discurso e argumentação na política latino-americana, set.2018.

\section{6. "Néo-fascismos" e/ou "direitas radicais" na Europa?}

Parece-me difícil fixar a data em que se começa a difundir o composto "neo-fascismo". Nos imediatos anos de pós guerra, o "velho" fascismo se perpetua num grande número de "fiéis" obstinados e ele sobrevive clandestinamente; ele não é ainda o "neo" que se mantém! As publicações nostálgicas que aparecem na época (na França, o tipo está nos livros de Maurice Bardèche e aqueles de Jacques Isorni, o defensor de Pétain) se qualificam melhor de "paleo-fascismo". Até o fim dos anos de 1970, o fascismo podia parecer, para as mentes sóbrias, desaparecido ou reduzido ao estado "ultra-grupuscular" e este, por toda a Europa. Dois regimes, na Espanha e em Portugal, eram provenientes da era fascista, mas eles atingiram o estágio de decadência estagnante e de senilidade antes de seu desaparecimento anunciado.

As primeiras análises que identificam um "neo-fascismo" em emergência remontam entretanto os anos de 1980. Elas mostram, na França e geralmente na Europa, após um período de relativa clandestinidade, as reaparições no grande dia de ditos "nostálgicos" mas também a criação de movimentos de direita radical com novos desafios, de novos cavalos de batalha como aquele da imigração que tomará rápido a linha de frente. De tais movimentos, observados no estado emergente e grupuscular, mas dos quais alguns puderam em seguida aumentar, eles tinham ainda na Europa a significação de uma continuidade fascista e um potencial histórico? Por volta de 1950, as pessoas que sempre se diziam fascistas na Alemanha não eram mais que $3 \%$, mas estávamos talvez em direito de manter os temores apesar desta estiagem aparentemente baixa.

Podemos avançar uma definição elementar que era relativamente precisa até o momento de absorção-mutação da entidade em uma nova categoria, uma categoria desenterrada e reintroduzida, o "populismo" - eu vou mais a fundo. O termo neofascismo (ou neo-fascismo) designaria os movimentos políticos posteriores à Segunda Guerra mundial que se inspiram no fascismo italiano ou que se reivindicam de todo ou em parte de sua ideologia: o neo-fascismo se caracterizaria pelo ultra-nacionalismo, a xenofobia, o anticomunismo, a hostilidade ao sistema parlamentar e à democracia liberal. É então a propósito de certos movimentos do pós-guerra do qual nenhum reivindica expressamente de um regime abolido - se este não for o MSI italiano - que a questão de qualificação se coloca se queremos evitar 
EID\&A - Revista Eletrônica de Estudos Integrados em Discurso e Argumentação, Ilhéus, n. 16 esp. "Discurso e argumentação na política latino-americana, set.2018.

o "fascismo" a um espectro que assombra o imaginário de esquerda e a um termo exorcístico que permite qualificar assombrosamente toda personalidade e toda política que Ihe desagrada. Apesar disso, mesmo com um certo esforço de delimitação, o ainda designado "neo-fascismo" parece a todo momento em vias de se dissolver na insegurança denunciadora e a perder ipso facto toda utilidade crítica. Apesar de alguns esforços para inscrever seu alcance e tornar eventualmente a categoria útil ao cientista político, "neofascismo" é efetivamente um tipo de invectiva sintético que faz convergir em um todo detestável nacionalismo, xenofobia, racismo, antisemitismo, e os recentemente adicionados "sexismo" e "homofobia". Supõese precisamente que se opere automaticamente em certas mentes uma convergência e somatórias fatais de diversos ódios do "Outro".

O neo-fascismo foi às vezes confundido, num sinônimo de repulsa, com "neo-nazismo" - esse último composto colocando especialmente antes da acusação de racismo e estando aplicado segundo o caso dos skinheads e outros hooligans, os supremacistas brancos, os negacionistas.

A tendência à extensão de "neo-fascismo" categoricamente mais ou menos radical, conservadora ou liberal, e mesmo a toda expressão de um patriotismo reputado necessariamente xenófobo e racista, tendência carregada pela tradição antifascista, se faz sentir mesmo na pesquisa de aspecto universitário. Anthony J. Gregor consagrou um livro, The Search for Neofascism, para mostrar que a noção de "neo-fascismo" é inaplicável, que ela é vazia de sentido, deve ser abandonada, especialmente pelos universitários que se servem dela com excessiva facilidade. Nós devemos, ele assegura, deixar a palavra às discussões de bar. Os utilizadores desse termo, acadêmicos ou "leigos", não tentam mesmo, observa Gregor, ligar os fenômenos ainda etiquetados ao regime de Mussolini ou a sua idelogia. "Several lifetimes after Mussolini's Fascism disappeared into history, its specter still troubles the research of some of the most industrious social scientists". O italiano Renzo De Felice foi igualmente opositor a toda extensão do "fascismo" além de 1945.

Se tratava-se de qualificar e denunciar os regimes políticos contemporâneos, "néo-fascismo" | "neo-nazismo" designaram sucessivamente: A África do sul do Apartheid (regime fascista abolido em 1991), a ditadura dos coronéis na Grécia de 1967 à 1974, resultado do golpe de Estado dirigido pelo general Papadópoulos, a ditadura militar chilena de 
EID\&A - Revista Eletrônica de Estudos Integrados em Discurso e Argumentação, Ilhéus, n. 16 esp. "Discurso e argumentação na política latino-americana, set.2018.

Augusto Pinochet (1973), a Junta dirigida por Jorge Videla na Argentina (1976). Todas faces de um "fascismo" de acepção muito ampla, mas repressiva, criminal e condenável. O termo foi ainda aplicado, pelas mídias e às vezes por fontes acadêmicas, aos regimes ditatoriais árabes como aquele de Muammar al-Qaddafi e aquele de Saddam Hussein. A Enciclopédia Britânica Online, escrita autorizada de Robert Soucy fez uso dele para o Iraque até 2003 e o justifica brevemente: "Hussein's regime was essentially a personal dictatorship based on an Arab version of the Führerprinzip".

A extensão do termo se torna ainda mais incerta e discutível quando, nos anos de 1980, os publicistas liberais concebem aplicar "neo-fascismo" ao megalômano, repressivo e chauvinista regime romano de Nicolae Ceauşescu mas "neo-estalinismo" fazia o negócio e "estalino-fascista" é atestado. O regime ultra-nacionalista sérvio, dito "pós-comunista”, de Slobodan Miloševič se viu conceder em seguida as mesmas designações. Sem dúvida, até nesses anos de 1980, "neo-fascismo" não foi quase nunca aplicado, seja pela grande imprensa ou pelo mundo acadêmico, a outros regimes que de extrema direita e a algumas ditaduras caudilhista sul-americanas de coloração incerta, enquanto todos os parâmetros da somatória do tipo ideal se aplicavam bem ao genocida "Kamputchea democrática" ou ainda à Albania "comunista" autárquica de Enver Hodja. As reticências foram dissipadas, mas a extensão sem teorização aos regimes reputados de esquerda, foi ao único nível de sua retórica propagandista, aumentou se foi possível a confusão. Encontra-se, por exemplo, ocasionalmente, na imprensa hoje a qualificação de "neo-fascismo" para caracterizar a ditadura "pós-comunista" de Alexandre Loukachenko na Biélorrússia: culto da personalidade, economia dirigida, monopólio de mídias, terror policial, supressão da oposição, vontade de controle total da população, encontramos também certos parâmetros exigidos que parecem autorizar a caracterização-transposição, mas elas não estão fundamentadas em nenhuma teorização nem historicização. É na medida em que os parâmetros academicamente estabelecidos para distinguir o fascismo "na sua época" de "simples" ditaduras dos anos de 1930 se aplicam muito bem a diversos regimes contemporâneos cuja origem cultural, a ideologia, ou, em todo caso, a propaganda, e a situação geográfica são incomensuráveis que a aplicação fora do contexto entre as duas guerras é repudiada - não porque ela não "se aderia", mas em realidade porque ela funciona muito bem sem, entretanto nada explica. 
EID\&A - Revista Eletrônica de Estudos Integrados em Discurso e Argumentação, Ilhéus, n. 16 esp. "Discurso e argumentação na política latino-americana, set.2018.

O historiador Pierre Milza preferiu, por sua vasta síntese europeia, A Europa em camisa preta, utilizar a categoria mais neutra de "extrema direita" abordada com um dado permanente da vida política de pós-guerra e não neoalguma coisa, - direita extrema que é um contraponto pela esquerda... e sempre uma caixa de ideias para as direitas de governo.

As razões para entregar ao seu próprio destino confuso "neo-fascismo" como "neo-nazismo" abundam então... Entretanto, não podemos negar as continuidades e mesmo as explícitas vontades de continuidade. Acontece que na Itália, com a l'Alleanza nazionale, na Áustria, Alemanha, Sérvia, Croácia, Rússia e em outros lugares como no supra indicado Pacto de Varsóvia, na África do Sul, nos Estados Unidos igualmente, se desenvolveram no decorrer de 1990 e até nossos dias, os movimentos tão tipicamente copiados e inspirados em "modelos" fascistas-nazi-racistas (o negacionismo, primeiramente) que não se pode refutar a etiqueta "neo-fascismo" altamente reclamada por eles. Stanley Payne admite que após 1945, se o regime fascista desapareceu, os fascistas em número reduzido sobreviveram em vários países e dentro de vários países eles, pouco a pouco, retomaram vantagem sobre o adversário.

\section{O “nacional-populismo", uma descendência fascista atenuada?}

Reconhecemos, sem muito esforço, nesses últimos anos que, tanto nos discursos de estudiosos como na mídia e na doxa política, uma palavra vem proliferando - palavra esta que esteve ausente do léxico antes de 1990 ou que provinha de um passado distante: a palavra “populismo”. Esta categoria não tinha até então outro uso que não o acadêmico, especializado, para designar, em francês, os movimentos políticos estrangeiros que apareceram no século 19; na Rússia, desde a década de 1860, os narodniki do Império Russo que “iam ao povo" e sonhavam restaurar uma comunidade perdida; e, nos Estados Unidos, na década de 1890, o populismo rural hostil às políticas das "elites" desconectadas de Washington, populismo muito americano, plebeu, que, como vê-se hoje, sobrevive em longa duração.

Inicialmente, a categoria foi desenterrada, saiu do esquecimento para designar de maneira pejorativa os movimentos antiparlamentares e declaradamente xenófobos, como o Partido da Liberdade da Áustria (Áustria), o Partido Popular Dinamarquês (Dinamarca), o Partido pela Liberdade (Países Baixos), os Verdadeiros Finlandeses (Finlândia). Direito e Justiça (Polônia), 
EID\&A - Revista Eletrônica de Estudos Integrados em Discurso e Argumentação, Ilhéus, n. 16 esp. "Discurso e argumentação na política latino-americana, set.2018.

Jobbik (Hungria), Liberdade e Solidariedade (Eslováquia), Partido Democrático Cívico (República Checa), Partido dos Cidadãos Livres (República Checa), Alternativa para a Alemanha (Alemanha)... Alguns historiadores nos anos pósguerra desenterraram, por sua vez, a palavra "populismo" com o objetivo de matizar suas análises dos chamados fascismos fora da Europa. O fascismo poderia ser reduzido a um populismo autoritário, a um "nacionalismo populista". Veremos aqui Gino Germani e seu Autoritarismo, Fascismo e Populismo Nacional, que ilustra a convergência dessas noções pelo estudo do peronismo, um regime que ele conheceu de perto. $\mathrm{O}$ apoio das classes dominadas, trabalhadores e camponeses, conjugado à pequena burguesia é frequente nos caudilhismos sul-americanos; pode ser visto na revolução mexicana de 1910-20, no MNR boliviano, por exemplo, como também se observa no peronismo com seus lados de socialização, sua demagogia que seduz os pobres e os excluídos ao reivindicar atacar as castas privilegiadas corrompidas.

"Populismo" e seus híbridos e derivados, em primeiro lugar, "populismo nacional" - trago-os abaixo - é um termo altamente impreciso, sempre conotado de forma pejorativa, que se tornou muito "na moda", mas infinitamente polissêmico e controverso. São dezenas de milhares de ocorrências em todas as línguas do "Ocidente", se contarmos com o Google. Devido a esse excesso de emprego confuso, a palavra rapidamente seguiu a queda fatal da perda de significado que tinha sido o destino dos outros -ismos anteriores, os quais acabei de mencionar; os usos recentes da palavra "populismo" parecem ter tomado o mesmo rumo que as palavras "fascismo" e "nacionalismo" em linguagem corrente: o abuso polêmico fez destes termos uma etiqueta de desqualificação e um operador de amálgamas.

Assistimos a uma proliferação, em língua francesa, de livros e números especiais, todos contraditórios sobre um "populismo" supostamente em progresso e ameaçador - à medida que o uso do fascismo foi se desgastando a ponto de já não ser aceito e à medida também que certas convergências ideológicas entre extremistas da direita e da esquerda começaram a atacar observadores liberais e centristas. Neste contexto, a prestigiada revista Crítica fez a observação em 2012 de uma dilatação semântica da palavra ao transpor o início do Manifesto Comunista: "Um espectro assombra a Europa, qual seja: o do populismo. E a França, neste ano de eleições presidenciais, não é poupada. Poucos editoriais, guerra de debates nos quais [o grito] 'populista!' é lançado 
EID\&A - Revista Eletrônica de Estudos Integrados em Discurso e Argumentação, Ilhéus, n. 16 esp. "Discurso e argumentação na política latino-americana, set.2018.

contra o oponente como se gritassem: 'anátema!'. Com tantos usos, uma palavra se desgasta rapidamente. Daí o cansaço do cidadão público e a tentação de jogar o bebê com a água do banho fora". Sinônimo de demagogia, a palavra tornou-se mera injúria política.

O que é curioso é que o termo foi, de início, apresentado, penso, em meios cautelosos, acadêmicos, foi desenterrado precisamente para evitar recorrer a todas as categorias da polêmica popular, vazias de sentido, que têm como exemplo auge a palavra "fascismo" - insulto. Os cientistas políticos, preocupados em mensurar, preocupados em se distanciar de um uso puramente fabuloso, reviveram e reajustaram o conceito de "populismo nacional [ista]" para classificar com alguma ponderação e veemência menos hostil o Front National na França, por exemplo, para caracterizar a ideologia mantendo à distância o fantasmagórico "fascismo".

Na mídia, por outro lado, o "populismo" é mais do que nunca um instrumento de reprovação e estigmatização. Taguieff (2002), depois de 200 páginas de discussão acirrada em um ensaio, L'illusion populiste, procura recuperar o termo e delimita seis domínios de significação - populismomovimento, populismo-regime, populismo-ideologia, populismo-atitude, populismo-retórico e o populismo-tipo de legitimação - que se encontram como usos definidos, pertinentes e operacionais. O populismo se polariza em dois subtipos, protestador (reivindicando o povo-dêmos) e identitário (povoethnos) com uma distribuição de casos híbridos que podem ser ilustrados através de exemplos em toda a Europa de hoje. Duzentas páginas, dirão as mentes populistas (!), para acabar definindo uma noção intuitiva e confusa e estabelecê-la como uma tipologia? Sim, é o preço do trabalho intelectual. A multiplicidade e a diversidade dos movimentos confrontados e a variedade de seu sucesso - Le Pen na França, Silvio Berlusconi na Itália, Jörg Haider na Áustria - não contradizem necessariamente a unidade ideal-típica do fenômeno. A questão a se colocar é saber se as abordagens do populismo estão fadadas a explorar apenas essa pluralidade empírica sem exceder os limites, ou se é possível construir um modelo geral de populismo, para além das múltiplas configurações populistas observáveis. "Nacional-populismo", especifica Taguieff comparando tendências na Europa, no que diz respeito à Frente Nacional na França, é caracterizado por ele como "uma mistura de bonapartismo, de populismo reacionário com uma dominante nacionalxenofobia, senão racista, de democracia populista como na Suíça e de 
EID\&A - Revista Eletrônica de Estudos Integrados em Discurso e Argumentação, Ilhéus, n. 16 esp. "Discurso e argumentação na política latino-americana, set.2018.

populismo de políticos". Pode-se ver que Taguieff exclui expressamente o tal falacioso e vazio de sentido "fascismo", uma que ele considera "extrema direita" como algo impreciso e muito polêmico. O historiador das ideias atualizou seu pensamento em outro ensaio, Le nouveau national-populisme ( $O$ novo nacional-populismo), publicado em 2008, no qual ele se permite supor o que seria um futuro a médio prazo, um futuro que ele vê favorável às demagogias populistas condenadas a "corromper as democracias representativas de seu interior", mas, como tal, réplicas reativas, compreensíveis a este respeito, com a sua polarização para os extremos, suas variantes de direita e agora de esquerda, até o cruciante topo "neoliberal" thatcherista, axioma do "pensamento único": "There is no alternative, não há alternativa".

Avatar tardio do fascismo (tomando esta palavra, avatar, no sentido forte de metamorfose, de mudança de todas as aparências), com a preservação, por assim dizer, de sua essência funcional de ser uma reação radical contra o materialismo e o individualismo "modernos", acompanhada de uma rejeição dos costumes parlamentares, da classe dominante e centrada na busca de um Salvador. Eu não sonho em falar de um fascismo dissimulado, mas efetivamente transformado em outra coisa em uma conjuntura mundial nova e inesperada. Vejo no presente nacional-populismo uma mutação viral, provocando uma tensão, se quisermos, menos virulenta, mas sempre patogênica, do fascismo reduzido a seu núcleo elementar: uma demagogia de declínio nacionalista que contém ingredientes "nem de direita, nem de esquerda", e a identificação de novos inimigos do povo, internos e externos diante de um mundo desestabilizador e ameaçador.

Outros historiadores e cientistas políticos, preocupados em mensurar, concordaram em manter o conceito de "populismo nacionalista", e isto sempre em vista de classificar com menos veemência a FN longe do fantasmagórico "fascismo". "Guardemo-nos das fórmulas estereotipadas", adverte Pierre Milza ao recusar, por sua vez, o uso puramente exorcizador do "fascismo" pela esquerda e pelos autoproclamados "anti-racistas". Maurice Tournier avançou, por seu turno, para uma definição genérica em seis pontos do "populismo", no qual ele insiste sobre a busca de um bode expiatório: "Entenderemos por este termo todo discurso que, em vista da conquista ou da conservação do poder, tem como alvo as massas populares, praticando para com elas uma manipulação que as incita a uma desconfiança, uma 
EID\&A - Revista Eletrônica de Estudos Integrados em Discurso e Argumentação, Ilhéus, n. 16 esp. "Discurso e argumentação na política latino-americana, set.2018.

hostilidade, possivelmente um ódio no que diz respeito a uma entidade social particular responsabilizada por suas dificuldades de viver. Situamos assim o "populismo" na intersecção de seis temas: poder político, massas populares, frustações, propaganda, hostilidade, bode expiatório”.

Vários publicitários enfatizam as afinidades do dito populismo e do que se designa como a política-espetáculo, a partir da ideologia de ocupação "espontânea" do mundo da mídia que o aprecia e o pede de volta. Esta considerável convergência de duas demagogias cúmplices é salientada por Dominique Reynié em L'avenir du populisme (O futuro do populismo):

\begin{abstract}
Os populistas mantêm um discurso simplificado, radical por natureza, que jamais pedimos explicações. Eles se expressam com uma espécie de total liberdade. Os populistas desenvolvem um discurso que é em si mesmo espetacular: é uma dificuldade, sobre a qual convém trabalhar seriamente, de constatar até que ponto as mídias em seu conjunto manifestam uma forma de empatia, de cumplicidade ou de familiaridade com o discurso populista, porque trata-se de um discurso que, em si mesmo, espetaculariza-se. As mídias, a televisão e a rádio em particular implementaram, por exemplo, toda uma série de emissões híbridas, que se situam entre a diversão e a informação, entre o cômico e o sério, que constituem as verdadeiras máquinas para desmoralizar os líderes políticos e sociais convidados nessas emissões, onde se zomba deles, de seus tiques, de seus comportamentos, etc.
\end{abstract}

\title{
8. O populismo de esquerda
}

Li um ensaio de Dominique Reynié, Populismes: la pente fatale (Populismos: o declive fatal). O que é, para este publicitário liberal, o populismo? Não somente uma grande concha de demagogia, mas um paradigma ideológico que apresenta um núcleo ideal-típico, "uma visão política breve e bruta opondo, de um lado, um povo abandonado, até mesmo espoliado, e, de outro lado, as elites incompetentes, ou mesmo corrompidas. O populismo aparece em tempo de crise. O de hoje resulta de uma conjunção temível: globalização econômica, envelhecimento demográfico, esgotamento das finanças públicas e recomposição étnico-cultural da sociedade”. A partir disso, Reynié afirma observar uma "rivalidade mimética" dos extremos, em que ambos se integram num populismo genérico. $O$ mesmo Dominique Reynié, em La vertige social-nacionaliste: la gauche du Non (A vertigem socialnacionalista: a esquerda do Não) já havia denunciado em 2005 uma convergência dos populismos de esquerda e de direita, durante o referendo francês sobre a Constituição europeia: dos adeptos à antiglobalização aos 
EID\&A - Revista Eletrônica de Estudos Integrados em Discurso e Argumentação, Ilhéus, n. 16 esp. "Discurso e argumentação na política latino-americana, set.2018.

dissidentes do Partido Socialista, passando pela Liga Comunista revolucionária, pelos ecologistas e pelo Partido Comunista Francês, a esquerda do Não mobilizou "um anti-liberalismo feroz, um estatismo fanático, e um chauvinismo impregnado de xenofobia. Tudo o que Léon Blum, em seu tempo, denunciava como um programa 'nacional-socialista”".

O que choca a esquerda é a inclusão pelos "moderados" em uma categoria Ni droite, ni gauche (Nem direita, nem esquerda) de dois extremos da topografia política, a "fascista" Marine Le Pen e os últimos herdeiros do "antifascismo", que, ao atacarem a classe dominante e a alta finança, reivindicam lutar na primeira fileira e também contra Le Pen, pai e filha, contra a Frente, seu nacionalismo, seu ódio e seu medo de imigrantes, sua xenofobia - inclusão resultante, ainda, da comparação feita pelos jornalistas do Monde entre os programas antissistema, convergindo sobre mais de um ponto a Frente de esquerda e a Frente nacional. O apelo à mudança total de "pessoal" político, desde o boulangisme dos anos 1880 até 2017, desdobra-se em algumas fórmulas indestrutíveis: acabar com a desordem estabelecida, abolir a corrupção reinante, destituir as elites que traíram o povo, romper radicalmente com o "sistema", refundar a democracia...Para limpar os estábulos de Áugias, é necessário, por vezes, um guia e um salvador para o povo. Quando o homem providencial surge? Quando a sociedade atravessa um período de desordem social, econômica ou moral, quando experimenta uma crise de confiança avessa em suas elites. A crise do euro, a pressão dos mercados financeiros, a impotência do Estado, a fragilidade do "poder público" no seu papel tutelar e a comprovada impotência da esquerda "de governo" preocupada em fazer "sonhar", a recomposição étnico-cultural da França induzida pelo envelhecimento e pela imigração favorecem e alimentam esta temática populista.

O gosto pelas teorias da conspiração parece selar especialmente a convergência dos populismos. A lógica conspiratória que até os anos 1970 era prerrogativa de uma extrema direita desestabilizada pelo curso do mundo, floresce, doravante, na "esquerda" antiglobalização. À direita, nada de mais "lógico" por dois séculos: aqueles que pensam que as tradições são sacrossantas, e que as veem se corroer sob os golpes inexoráveis da modernização, podem pensar que esta corrosão é orquestrada por vilões. O raciocínio conspiratório parte de algo lógico: se uma série de acontecimentos desagradáveis foram identificados, procuremos as causas, ou, seria mais 
EID\&A - Revista Eletrônica de Estudos Integrados em Discurso e Argumentação, Ilhéus, n. 16 esp. "Discurso e argumentação na política latino-americana, set.2018.

propício, mais simples e mais claro, a Causa. E para fazer isso, vamos remover as "cortinas de fumaça". A conspiração descoberta permitirá "fazer entrar para o racional" e para o explicável aquilo que aparece inicialmente como desanimador e inexplicável: a esse respeito, não se pode negar o produto de um esforço de racionalidade, há uma "função cognitiva", mesmo que seja distorcida. Seu caráter considerável resulta do fato de que esse esforço racional desemboca no ódio legítimo e alimenta o ressentimento. Ora, a "diabolização" do adversário e de seus objetivos, a criação de um adversário diabólico que é importante aniquilar, são fenômenos em progresso em todas as direções nos dias de hoje, como o ilustre estudo recente de O'Rourke, Demons by Definition: Social Idealism, Religious Nationalism and the Demonizins of Dissent. Não por acaso que as palavras diabolização/demonização passaram ao vocabulário das mídias - e para as bocas de todo mundo. "O imaginário da conspiração" analisado por Taguieff tem novamente bons dias pela frente. - A conspiração é bem ilustrada pela direita por meio do discurso "antiglobalização" da Frente Nacional que o remonta há vários anos e que o controla melhor que seus concorrentes. "Não somente todos os infortúnios do país devem ser explicados pela ação oculta de potências negativas, mas os obstáculos encontrados pelo movimento nacional-populista, e claro, seus fracassos, só podem ser explicados pela existência de uma conspiração a fim de dominar e destruir 'a França”", explica Taguieff. A teoria da conspiração tem a vantagem de oferecer uma explicação pseudo-causal tanto da "decadência" quantos dos fracassos do movimento nacionalista (sobre o assunto já discutido: "é culpa da Internacional judaica, da Internacional maçônica...)".

Até recentemente, para desmoralizar determinados "radicais" dos movimentos ecologistas que parecem pegar emprestado os temas da direita conspiratória e xenófoba, criou-se o combinado "verde-marrom" - e para descreditar, pela suspeita de convergências similares, a Frente de esquerda, encontra-se a fórmula "vermelho-marrom", - vermelho-marrom designa uma pessoa ou um movimento político que defende valores híbridos, uma mistura entre aqueles da extrema direita nacionalista (o marrom dos nazistas) e da extrema esquerda doravante comunista (o vermelho).

Este adjetivo composto, que também mereceria um estudo, "vermelhomarrom", emergiu após os conflitos balcânicos dos anos 1990, enquanto figuras sérvias como Slobodan Milosevič passaram do comunismo titoista para 
EID\&A - Revista Eletrônica de Estudos Integrados em Discurso e Argumentação, Ilhéus, n. 16 esp. "Discurso e argumentação na política latino-americana, set.2018.

um nacionalismo étnico sanguinário, destinado a purificar pela força a Grande Sérvia dos Croatas, dos Bosno- Muçulmanos e dos Albaneses, - mas o composto foi assumido e nós vemos isto reciclado hoje de um modo cada vez mais polêmico contra o que os outros chamam - designação não menos confusa - "esquerda da esquerda" que convergiria demonstrando-se antieuropeia e "soberanista" como a direita "nacional".

\section{Está morto há meio século ou sobrevive o fascismo?}

O fascismo morreu em 1945 como um regime antidemocrático, militarizado, racista e totalitário (pelo menos, ambicionava sê-lo). Ele não voltará e não precisará exorcizar uma quimera. Mas - ele sobrevive e sobreviverá por muito tempo, por outro lado, como um estado de espírito, como uma aspiração, como um símbolo de "autoridade absoluta em uma comunidade absoluta" e - não é que ele retornará: ele já retornou como tal na vida política de muitos países em avatares inesperados, sob outros nomes, em todas as formas diferentes, menos virulentas, de reação à desordem econômica, aos fluxos migratórios, às desilusões ante a impotência das democracias, às resistências em face da transformação do planeta em um imenso mercado conjugado para uma sociedade de vigilância em uma uniformidade que evoca a sombra do "totalitarismo" - retorno metamórfico para o qual pode ser usada a categoria de "populismo nacional" na medida em que permite, como qualquer rótulo tipológico, fixar parâmetros, e convida a comparações frutíferas.

É exatamente por esse tipo de resposta paradoxal e contrastante que Pascal Ory, grande historiador cultural, conclui seu ensaio, "Sobre o fascismo" I Du fascisme: "O fascismo está morto? Do meu ponto de vista, sim. ... o fascismo renascerá? Já renasceu sob outros nomes”. É este desaparecimento definitivo e este renascimento comprovado que fundam a relevância do estudo do fascismo contra a tendência não menos inadequada de transformálo "em coisa do passado". Está morto, então - ou sempre renascendo e agindo? É uma questão que é mal colocada e é facilmente reformulada em várias áreas na tentativa de fornecer respostas modestas. Existe um "fascismo" que é um estado de espírito, anti-racionalista, vitalista, antidemocrático, autoritário, xenófobo. Se o fascismo alimenta o medo de evoluções desestabilizadoras, então "naturalmente" vai proliferando, a torto e a direito, o medo de imigrantes, de estrangeiros, do Islã, da absorção da 
EID\&A - Revista Eletrônica de Estudos Integrados em Discurso e Argumentação, Ilhéus, n. 16 esp. "Discurso e argumentação na política latino-americana, set.2018.

nação na União Europeia "burocrática". Tal estado de espírito que revive a longo prazo com o nacionalismo revanchista de um Maurice Barrès, com todo o "pré-fascismo" cultural que data da década de 1880 e com os ContreLumières, é imortal. Não há razão para supor que ele tenha desaparecido, apesar de seu refluxo ser menos virulento. Isso pode estar relacionado com os relativismos de identidade e comunitarismos que também são, na minha opinião, o doce avatar contemporâneo com aparência enganosa de ouro de esquerda. Além disso, nada nos permite especular sobre as formas mais violentas que poderia assumir em um dia de grave crise, ou sobre sua eventual preponderância.

O britânico Roger Griffin, com sua definição de "ultra-nacionalismo palingenético", vê o mesmo se perpetuar nos nossos dias, uma ideologia pluridimensional e flutuante que não pode desaparecer completamente enquanto muda muito e é suscetível a metamorfoses inesperadas. O fascismomovimento de massa, o totale Mobilmachung e o regime totalitário e militarista pertencem, em contrapartida, a uma época passada - o que não significa que o Estado de Direito e a democracia naturalizados e estabilizados no Ocidente sejam um fato adquirido e que nenhuma crise profunda poderia colocá-los a baixo. Este é o único mérito da lembrança dolorosa da era fascista, como um "dever de memória" com sua irritante parte de falsa / boa consciência: um Ocidente que não teria entendido o imenso perigo representado pelo fascismo e a chance de que por ele tivesse sua aniquilação em meados do século passado seria bem desarmada, não confrontada com réplicas improváveis de forma idêntica, mas em face do simples fato de que nada é jamais adquirido, a democracia, a relativa justiça social e os direitos individuais menos que o resto. Roger Griffin persiste, então - contra a maioria de seus colegas - na tese da durabilidade do fascismo, transitoriamente aniquilado em 1945 e mantido em vigor durante a Guerra Fria, mas renascido sob novos engodos no populismo de direita. Veja como ele argumenta sua posição:

Em contraste com a maioria dos historiadores, vejo o fascismo como tendo uma importante vida após a Segunda Guerra Mundial ter acabado, entrando em um segundo período de vitalidade, embora fortemente diminuída, vitalidade esta como um projeto ideológico pós 1945. Certamente a visão de uma comunidade nacional renascida tinha sido tão desacreditada na mente do público em geral pela catástrofe da Segunda Guerra Mundial e pelo genocídio nazista que particularmente nas condições de crescente estabilidade e riqueza no Ocidente capitalista e de repressão totalitária no Império Soviético - o fascismo foi de 
EID\&A - Revista Eletrônica de Estudos Integrados em Discurso e Argumentação, Ilhéus, n. 16 esp. "Discurso e argumentação na política latino-americana, set.2018.

forma abrangente negado como espaço político para se transformar em um movimento de massa durante a Guerra Fria. ... Ainda assim, correntes de um "ultranacionalismo palingenético" certamente sobreviveram à derrota dos dois regimes fascistas. Onde quer que os níveis de instabilidade sócio-política tenham se tornado críticos ou, por exemplo, quando a imigração em massa é experimentada como profunda ameaça à identidade, fascistas do "estilo antigo" - modelando-se no fanatismo se não na disciplina paramilitar dos nazistas combatentes de rua - surgiram em pequena escala para cometer atos de violência étnica.

\section{Quando tudo está terminado}

Podemos caracterizar o novo conformismo intelectual que reina hoje pela fusão de três parâmetros ecléticos e imprecisos, que podem ser considerados residuais: progressismo vago, relativismo morno, antifascismo difuso. Esses resíduos são, por sua vez, amplamente despolitizados e transformados em absolutos morais. O antifascismo impreciso, ampliado e generalizado torna possível definir a configuração do "pensamento correto" contemporâneo. No que diz respeito a essa sobrevivência suave e contornos indefinidos, amalgamados com um humanitarismo sentimental, inconsistente e hipócrita, Taguieff (2005) afirma:

O antifascismo constitui, na verdade, uma tradição político-ideológica aos poucos naturalizada, cuja persistência é indissociável de uma ampliação que recentemente tomou a forma de uma generalização. $O$ antifascismo contemporâneo não deve ser reduzido a escritos militantes e às ações mais ou menos espetaculares de pequenos grupos que se autodeclaram "antifascistas", como Ras l'fore. O antifascismo generalizado foi constituído pela integração do anti-racismo (ele próprio ampliado para a "luta contra todas as discriminações"), o antinacionismo (a nação denunciada como a principal causa das guerras modernas), o anticolonialismo e anti-imperialismo (estilo leninista, depois terceiro-mundista), o democratismo (como culto da democracia), a invocação dos direitos humanos, o dever da memória e a conduta do arrependimento.

Devemos também levar em conta suas recentes extensões, a começar com o anti-sionismo, um "anti-ismo" que deve ser entendido no sentido forte do termo, implicando na demonização em blocos de Israel e do sionismo, forma hoje dominante de anti-semitismo e seu modo de camuflagem ou negação. ... “Essas múltiplas extensões são observáveis em campanhas permanentes contra uma série de monstros pós-modernos, tratados como 'sionismo': primeiro, a homofobia e a islamofobia (que devem ser entendidas, respectivamente, como o 'racismo anti-homossexual' e o 'racismo anti- 
EID\&A - Revista Eletrônica de Estudos Integrados em Discurso e Argumentação, Ilhéus, n. 16 esp. "Discurso e argumentação na política latino-americana, set.2018.

muçulmano'), em seguida, o racismo anti-juventude e o racismo antiimigrante".

Não é de hoje que a imprensa europeia não só sinaliza um retorno do fascismo, mas o formula, cômico pela força do uso, o que faz pensar em uma reminiscência da velha história de "Pedro que gritou aos lobos", não há dúvida de que estes gritos de alarme respondem a uma angústia difusa em sociedades desorientadas, em crise tão profunda quanto as de 1929. - "Como lutar contra o renascimento fascista na Europa?", perguntou Marianne, em 19 de setembro de 2013:

O assassinato do rapper grego Pavlos Fyssas por um militante da Aube Dorée soa com um chamado à ordem. Podem ainda prevalecer slogans antigos ao estilo: "o fascismo não passará", quando, na verdade, não só passa como mata. Quando Daniel Cohn-Bendit exclama: "É hora de nós, europeus, acordarmos antes que seja tarde demais", o que esse "tarde demais" significa?

As observações anteriores não nos convidam a concluir que, em nossa modernidade tardia, os mitos coletivos e as grandes cegueiras fanáticas deram sua última palavra, nem que os seres humanos foram, enfim, levados a olhar decididamente o mundo com um olhar sóbrio, da forma que Marx o desejava (em 1848) ou parecia vislumbrá-lo. A perda irreparável das grandes expectativas que animaram o Ocidente por dois séculos levou a quê? Sobriedade, razão serena? Não é tanto a resignação, a apatia, mas também o ressentimento e a angústia misturados com o entretenimento consumista? Os ensaístas do novo século, céticos, estão debatendo isso.

O homem do Ocidente "tornou-se definitivamente um enigma para si mesmo", ao mesmo tempo em que não pode mais transcender seu destino individual dedicado à morte e ao esquecimento, projetando a humanidade em um futuro melhor projetado, "vislumbrado". A dissolução da ideia de progresso é sinônima de uma "sublimação do futuro", de uma obliteração do futuro como promessa de salvação coletiva - esse fim é sinônimo do fim das utopias que, situadas primeiro por Thomas More e seus descendentes até os seus opostos estabelecidos pelo imaginário do final do século XVIII, em um futuro próximo. Outra mudança radical no estado da cultura: "Pela primeira vez em dois séculos, formula Martin Malia, o mundo não é mais uma utopia em andamento". "O futuro permanecerá sem rosto", ecoa Marcel Gauchet. Não exatamente o resto, seria bom demais para uma sobriedade cética. Se algo permanece vislumbrado, pela atual doxa, de um futuro próximo, esse 
EID\&A - Revista Eletrônica de Estudos Integrados em Discurso e Argumentação, Ilhéus, n. 16 esp. "Discurso e argumentação na política latino-americana, set.2018.

algo é simplesmente muito mais ameaçador que promissor: aquecimento global, ruína ecológica, inverno nuclear, pandemias etc.

E quanto ao "fascismo" metamórfico nessa mudança de época? A "Época Fascista" oferecia três campos claros: o comunista, o fascista e o democrata, e, portanto, escolhas claras (três, embora os comunistas só distinguissem dois deles dos campos). Em nossa época observamos uma fusão sincrética nos populismos das três opções anteriores, ou de elementos persistentes e reciclados deles próprios, com base em uma aparente aceitação do "jogo" democrático. O velho "reflexo antifascista" é impotente contra esse avatar e ele perde seu alvo enquanto a crise econômica, a queda de empregos e a fraqueza do Estado-nação em face do fluxo global alimentam de forma irreprimível os chamados populismos. A democracia agora reina suprema no Ocidente, constata Marcel Gauchet, no entanto, ele dá sequência, "encontrou seu oponente mais formidável: ela mesma". Muitos observadores ficam impressionados especialmente com o fato de que a vitória da democracia contra seus dois adversários totalitários é acompanhada por uma espécie de autodestruição "em um ativismo do qual ela se nega a querer completar": é possível que tornando-se realmente o "horizonte insuperável" do bem político (como dissera Tocqueville), ao ocupar a disputa sozinha por falta de adversários, a democracia chegou a absorver os espíritos da intolerância, do fanatismo e da ortodoxia, antes investidos pelos sistemas adversários.

\section{Referências}

ALAGZY, Joseph. La tentation néo-fasciste en France de 1944 à 1965. Paris: Fayard, 1984.

BENSOUSSAN, Georges. Auschwitz en héritage? D'un bon usage de la mémoire. Brève histoire de la destruction des Juifs d'Europe. Paris: Mille et une nuits, 1998.

CHEHABI, H. E.; LINZ, Juan (Dir.). Sultanistic Regimes. Baltimore: Johns Hopkins UP, 1998.

FURET, François. Le Passé d'une illusion. Essai sur l'idée communiste au XX siècle. 1995.

GAUCHET, Marcel. La démocratie contre elle-même. Tel Gallimard, 2002. 
EID\&A - Revista Eletrônica de Estudos Integrados em Discurso e Argumentação, Ilhéus, n. 16 esp. "Discurso e argumentação na política latino-americana, set.2018.

. La condition historique. Entretiens avec Fr. Azouvi et Sylvain Piron. Paris: Gallimard/Folio, 2005.

GOLSAN, Richard. Fascism's Return: Scandal, Revision and Ideology since 1980. Lincoln: University of Nebraska Press, 1998.

GOODRICK-CLARKE, Nicholas. Black Sun: Aryan Cult, Esoteric Nazism and the Politics of Identity. New York: New York UP, 2002.

GREGOR, James. The Search for Neofascism. The Use and Abuse of Social Science. Cambridge et New York: Cambridge UP, 2006.

GRIFFIN, Roger; FELDMAN, Matthew. Fascism: Critical Concepts in Political Science. London: Routledge, 5 vol., 2004.

. The Nature of Fascism. London: Routledge, 1993.

JOES, Anthony James. Fascism in the Contemporary World: Ideology, Evolution, Resurgence. Prefácio de A. Gregor. Boulder CO: Westview, 1978.

LARSEN, Stein Ugelvik. Fascism outside Europe. New York: Columbia UP, 2001.

LEE, Edwards. The Collapse of Communism. Stanford CA: Hoover Institution Press, 2000.

MACHEFER, Philippe. Ligues et fascismes en France, 1919-1939. Paris: PUF, 1974.

MEYER, Jean-André. Le sinarquisme, un fascisme mexicain? 1937-1947. Paris: Hachette, 1977.

MILZA, Pierre. L'Europe en chemise noire: les extrêmes droites européennes de 1945 à aujourd'hui. Paris: Fayard, 2002.

ORY, Pascal. La France allemande. Édition revue. Paris: Gallimard, 1995.

PAYNE, Stanley. A History of Fascism, 1914-1945. London: UCL, 1995.

RAMET, Sabrina P. The Radical Right in Central and Eastern Europe since 1989. University Park PA: Pennsylvania State UP, 1999

TAGUIEFF, Pierre-André. L’illusion populiste. Berg, 2002.

. La foire aux illuminés. Ésotérisme, théorie du complot, extrémisme. Paris: Mille et une nuits, 2005.

2007.

. Contre-réactionnaires. Le progressisme entre illusion et imposture. Denoel, 
EID\&A - Revista Eletrônica de Estudos Integrados em Discurso e Argumentação, Ilhéus, n. 16 esp. "Discurso e argumentação na política latino-americana, set.2018.

TOURNIER, Maurice. "Les mots fascistes, du populisme à la dénazification. Mots, n.55, p. 153-168, juin 1998.

TRINDADE, Hélgio. La question du fascisme en Amérique latine. Revue française de science politique, 33e année, n.2, p. 281-312, 1983.

. Integralismo: o fascismo brasileiro na década de 30. São Paulo: Difusão europeia, 1974.

Tradução:

Hulda Gomides Oliveira e Geovana Chiari

Doutorandas do Programa de Pós-graduação em Linguística da Universidade Federal de São Carlos (UFSCar).

Forma de citação sugerida:

ANGENOT, Marc. Fascismo, populismo: as utilizações contemporâneas de duas categorias políticas nas mídias. Trad. Hulda Gomides Oliveira e Geovana Chiari. EID\&A - Revista Eletrônica de Estudos Integrados em Discurso e Argumentação, Ilhéus, n. 16 esp. “Discurso e argumentação na política latino-americana”, p. 244-273, set.2018.

Recebido em: 25/07/2018

Aprovado em: 26/08/2018 